\title{
Reclassification for the Chinese Theological Collection
}

Josella Chan, Melbourne School of Theology

ABSTRACT: John Searle Library has undertaken a reclassification of the Chinese Theological Collection belonging to Melbourne School of Theology. It was found that Pettee Classification did not support cataloging sufficiently due to not being updated in decades. Reclassification of the collection was necessary. This paper discusses the decision-making process and how the new classification scheme for the collection was chosen. It describes the implementation of the reclassification project and reviews the outcomes.

It was decided to reclassify the collection to Library of Congress Classification. This resulted in improving information retrieval, increasing collection discoverability and visibility, and reducing staff time devoted to cataloguing and reference service. An interactive online LCC training module was developed to educate users. As a result, users were engaged and empowered to discover the collection effectively.

In conclusion, classification is not merely for shelving and retrieving items. It is the foundation of knowledge organization and also a core business to support many aspects of library service. Information professionals should rethink and reposition classification and transform it to a value-added service for the library.

\section{INTRODUCTION}

The John Searle Library in Melbourne School of Theology (MST) houses the Chinese Theological Collection (MSTC) for the use of Chinese students, alumni, faculty, and staff. The collections contain more than 18,000 items, including general collection, reference collection, and AV collection.

When MST, MSTC, and Eastern College moved their collections into the John Searle Library, the library found itself with two different classifications, Pettee Classification and Dewey Decimal Classification. Currently, MST English collections are using the Pettee 
Classification scheme, and the Eastern collection is using the Dewey Classification Scheme.

The Chinese Department found that Pettee Classification might not accommodate new items that deal with current theological concepts and subjects. They recommended that the bilingual librarian investigate the reclassification of the entire Chinese Theological Collection.

After investigation and discussion, the librarian proposed to reclassify the entire Chinese collection to Library of Congress Classification and submitted an implementation plan. The developed proposal was approved in October 2020. The project was implemented by the librarian in November 2020. Completion of this project is expected in 2021.

This paper discusses the decision to reclassify and the choice of classification scheme for a Chinese theological collection in a theological library. It also will describe the project implementation, review the results, and outline what lessons we have learned from this project.

\section{WHAT ARE THE ISSUES WITH THE EXISTING CLASSIFICATION SCHEMES?}

Some issues affect library users' ability to find information resources in the library. Firstly, multiple copies of the same title from different colleges are shelved in different locations. Secondly, the library users are confused with having to interpret different classification schemes.

Other issues affect the library cataloguing and staff time. First, the Pettee classification is no longer updated and has not been developed since 1966. Newly acquired items with current theological concepts may not find a suitable classification location for the associated content. Secondly, Pettee classification is rarely used in Chinese theological libraries. Most Chinese theological libraries either use the Library of Congress Classification or Dewey Decimal Classification. Therefore, the librarian became the sole user of Pettee and needed to use more of her staff time to catalogue and process new items. As a result, the librarian investigated the options of reclassification and made recommendation for the change. 


\section{CHOICE OF CLASSIFICATION SCHEME}

\section{Research of Best Practices and Professional Guidelines}

The American Library Association has recommended that if a library is using a local system or a classification scheme that is not maintained and updated, it should consider aligning the collection with a system that is maintained (ALA 2020). The Pettee classification scheme was developed by Julie Pettee for theological libraries in the early 20th century (Eisenhart 1960; Butler 2013), and has not been updated since 1966.

Reclassification of the John Searle Library was considered because the existing system was not workable and could not support the librarian to carry out classification tasks efficiently (Harvey and Hider 2004). The library needed to change to a new classification for its collection.

It led to the question of which classification scheme should be used to most benefit the library's users, maximize the productivity of library staff, and improve the library operation and workflow.

\section{Literature Review: Dewey or Library of Congress?}

It is well known that Dewey Decimal Classification (DDC) is the most popular scheme overall, being used in public and school libraries; whereas Library of Congress Classification (LCC) is commonly used in academic libraries in the US (ALA 2020; Butler 2013).

Since the rise of LCC in the mid-1950s, many academic libraries made the switch from DDC to LCC and have reclassified their collections (Steele and Foote 2011). Reclassification was much discussed in the professional literature during the mid-1950s through 1970s, and the focus usually was on the choice between Dewey and Library of Congress (Steele and Foote 2011).

2.1) The decline of using DDC in academic libraries in the US Dewey Decimal Classification (DDC) has been declining in US-based academic libraries for over six decades, from $80 \%$ to $13.5 \%$ (Lund and Agbaji. 2018). There are serval reasons that academic libraries prefer to use Library of Congress Classification (LCC):

- LCC uses alphanumeric notation which provides greater flexibility than DDC's numeric-only scheme. It was 
designed to offer a broader range of classes for the larger collections as well as breadth and depth for collection development.

- DDC has a limited number of classes that cannot capture all the categories represented in modern, large-scale library collections. A larger collection using DDC must be compacted into a very small range of less specific call numbers.

- DDC lacks breadth of classifying for non-Christian religions and non-white cultures (Higgins 2016).

- The proper placements of certain subjects have been questioned, e.g. Psychology as a subdivision under Philosophy (100s) (Chan 2007; Chan and Salaba 2015).

- Related disciplines are often separated, e.g. 300 (Social Sciences) from (900 (Geography and History); and 400 (Languages) from 800 (Literature) (Chan 2007; Chan and Salaba 2015).

- The capacity for numerical expansion is infinite, but it also results in lengthy numbers for specific subjects (Chan 2007; Chan and Salaba 2015). The long call numbers have been found inconvenient.

- Reclassification and partial collection relocation are often required when the new edition released (Gangu and Rao 2002).

- Theological library staff found it difficult to use DDC for the theological collection a century ago (Walker and Copeland. 2009). Pettee believed that DDC was not workable for theological libraries; as a result, she developed Pettee Classification when LCC was developing in early 1900s (Walker and Copeland. 2009; ACL 2017).

- Staff preference due to cost, size of collection, specialties of staff, mere exposure effect (employees prefer the system they currently use), or those who have been longexposed to DDC tend to prefer it to LCC or vice versa (Lund and Agbaji. 2018).

2.2 LCC is widely used in the American and Chinese theological libraries

Although DDC is commonly used in Australian theological libraries, LCC is widely used in American theological librar- 
ies (Butler 2013). Eisenhart (1960) also found that LCC was suitable to use for theological libraries. Most Chinese theological libraries in Hong Kong and Taiwan also use LCC for their collections.

There are some reasons that these academic libraries use LCC. These include:

- LCC provides main classes from A to Z, multiple subclasses, and divisions (Chan 2007; Chan and Salaba 2015)

- LCC call numbers are brief and are easily understood for shelving purposes (Chan 2007; Chan and Salaba 2015)

- The classification of regions has a wide spectrum of subclasses and divisions for the denominational source of religion materials, such as denominational history, both general and national, creeds and catechism, and liturgy (Eisenhart 1960).

- Atla supports the ongoing development of LCC in religion.

- Library of Congress provides quarterly updates to its theological classification and subject headings-for example, New and Changed LC Classification Numbers from November 2019 to February 2020 Lists, and New and Changed LC Subject Headings and Other Terms.

- Librarians can manage electronic resources seamlessly with the provision of LCC from Atla Religion and Philosophy database and e-book collection.

2.3 Australian Context: Classification schemes used in Australian theological libraries

In 2020, ANZTLA compiled statistics from data voluntarily provided by their member libraries (Stevens 2021). The survey revealed that DDC was commonly used in Australian theological libraries. This prompts the question as to why they prefer DDC over LCC. It is suspected that the library collection size and the classification used are correlated.

There were 36 respondents of the 60 institutional members. The report showed that $61 \%$ of library members have collection size less than 50,000 items, followed by $9 \%$ with less than 100,000 items, $8 \%$ with more than 100,000 items, and $22 \%$ did not provide their data (Figure 1).

This statistical report included inaccurate information that J. W. Searle Library currently uses Pettee/Dewey. After 
amendment, the report showed that 26 libraries used DDC (72\%), followed by four libraries with LCC (11\%), four libraries with Pettee (11\%), one library with Pettee/Dewey (3\%) and one library with Bonish (3\%) (Figure 2).

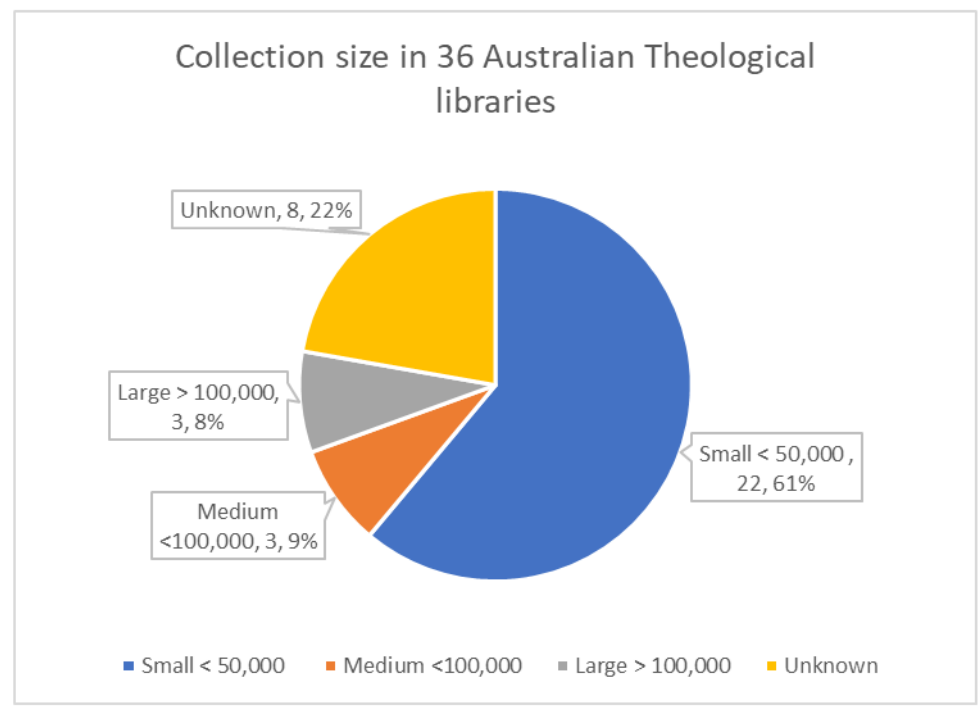

FIGURE 1: Collection size in 36 Australian Theological libraries

Classification Schemes used in 36 Australian Theological Libraries

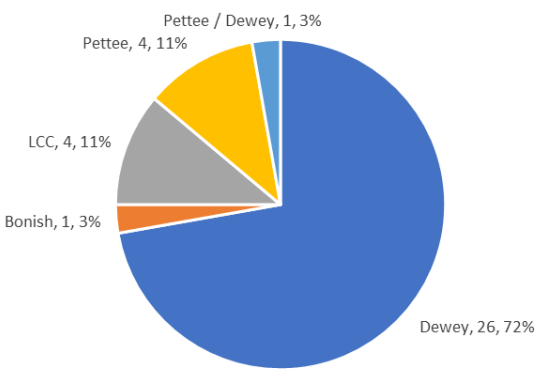

- Dewey - Bonish $\quad$ - LCC $=$ Pettee $\quad$ - Pettee/Dewey

FIGURE 2: Classification schemes used in 36 Australian Theological Libraries 
As seen in Figure 3, it found that $64 \%$ of Australian theological libraries with smaller collection size (less than 50,000 items) used DDC in 25 responses, and $12 \%$ of them used LCC. One library with medium collection size (55,234 items) used Dewey, and another library with 69,633 items used Bonish. Three libraries with large collection size (more than 100,000 items) used different classification systems: one large library used DDC, another one used Pettee, and our library had Pettee/Dewey.

These findings suggested that the Australian theological libraries which used DDC have smaller collections. Their collection may cover subjects in general and not too specific; so DDC may suffice to accommodate their needs. Interestingly, four libraries with smaller collection use LCC. It seems that LCC is not only suitable for larger academic libraries, but also for the smaller special libraries.

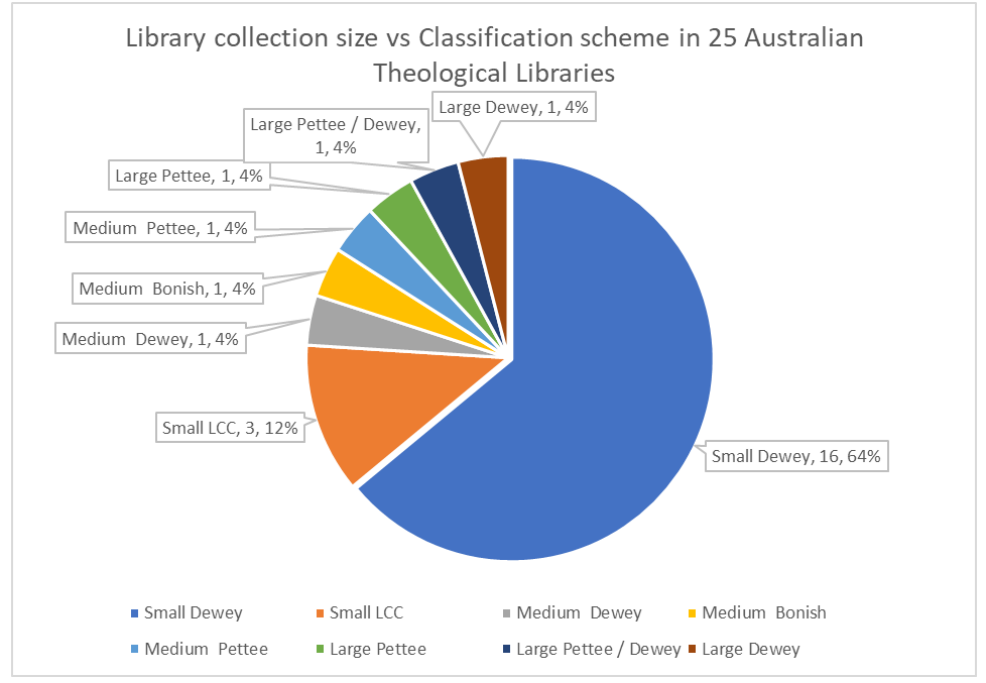

FIGURE 3: Library size vs Classification scheme in 25 Australian Theological Libraries

\section{Reclassification: Australian examples}

Reclassification of the library collections has occurred in Australia. Harvey and Hider (2004) recorded the reclassification of library collections carried out in academic and special libraries. 
- In early 1970s, University of Queensland moved from DDC to LCC; one factor was that more LCC classification numbers were at the time available from centralized cataloguing sources.

- University of Tasmania moved from BC to LCC; reasons were lack of updating the scheme and cost benefits of using standard classification.

- Griffith University moved from DDC to LCC.

- Australian Defence Force Academy Library in Canberra; one of the reasons: LCC better accommodates military, scientific, and technical materials. (Harvey and Hider 2004)

\section{Best Classification Scheme?}

All classifications are unsatisfactory in some way or another. Which classification scheme will work better for our library? Harvey and Hider (2004) provided the criteria to evaluate a classification scheme. These include:

- Is the scheme inclusive within its defined area, and is it comprehensive?

- Is the scheme systematic - is its structure logical and understandable?

- Is the scheme flexible and expandable - can it incorporate new subjects without disrupting its structure?

- Does the scheme's notation meet the criteria of uniqueness, simplicity, brevity, and hospitality?

- Is the scheme current and regularly updated? Is there an efficient mechanism for hospitality? Strong institutional support, maintenance, and updates are important.

- Is the terminology used in the scheme clear, unambiguous, and consistently applied?

- Does the scheme contain bias - can it be applied in a culturally, politically, or religiously neutral way? (Harvey and Hider 2004)

They further explained that the concepts of enumeration, hierarchy, and facet influenced the classification and shelf location. Enumerative schemes listed the subjects, loosely grouping related subject together. Faceted schemes started from a different basis, with subjects broken down into single concepts and a notation assigned to each item (Harvey 2004). DDC is enumerative, pure notation (only 
one type of symbol is used), and mnemonic. It is commonly used in general collections in libraries, such as public or school libraries. LCC has a mixed notation with facets and enumeration, the characteristics of uniqueness, simplicity, brevity, and hospitality. It is generally used in academic or college libraries.

How do these characteristics affect our library collections? An investigation was carried out. It found the problem that, for example, the call number 248.4 CHA had 35 results, consisting of 25 unique titles and 10 duplicates on the library management system. We found that the same call number could be repeatedly assigned to different titles. These items were reclassified with an LCC call number. In Figure 4, it is clearly shown that LCC has 25 unique call numbers to specify each item; whereas DDC assigned the same call number to generally classify the subjects and items.

\begin{tabular}{|c|c|c|c|c|}
\hline DDC & - LCC & Author & Title & Publication dat . \\
\hline $248.4 \mathrm{CHA}$ & BV4511.C52 1986 & & Changed! : reflecting your love for God. & \\
\hline $248.4 \mathrm{CHA}$ & BV4501.3.C426 2009 & Chalke, Stephen & Apprentice: walking the way of Christ & \\
\hline 248.4 CHA & BV4598.5.C43 2015 & Challies, Tim, 1976- & Do more better: a practical guide to productivity & \\
\hline $248.4 \mathrm{CHA}$ & BV4501.2 C43 1972 & $\begin{array}{l}\text { Chambers, Alice Mary, } \\
\text { 1934-2016 }\end{array}$ & Something more & 1972 \\
\hline $248.4 \mathrm{CHA}$ & BV4801.C43 1976 & $\begin{array}{l}\text { Chambers, Alice Mary, } \\
\text { 1934-2017 }\end{array}$ & This liberation thing & 1976 \\
\hline 248.4 CHA & BV4527.C254 1967 & $\begin{array}{l}\text { Chambers, Alice Mary, } \\
\text { 1934-2018 }\end{array}$ & When I consider : more thoughts for women & 1967 \\
\hline $248.4 \mathrm{CHA}$ & BV4502.C354 1985 & $\begin{array}{l}\text { Chambers, Alice Mary, } \\
\text { 1934-2019 }\end{array}$ & Christian disciplines: volumes 1 and 2 & 1985 \\
\hline 248.4 CHA & BV4811.C4553 1994 & $\begin{array}{l}\text { Chambers, Oswald, } \\
\text { 1874-1917 }\end{array}$ & $\begin{array}{l}\text { Devotions for morning and evening with Oswald } \\
\text { Chambers: the complete daily devotions of my utmost } \\
\text { for his highest and daily thoughts for disciples }\end{array}$ & \\
\hline $248.4 \mathrm{CHA}$ & BV4501.3.C434 2008 & Chan, Francis, 1967 - & Crazy love: overwhelmed by a relentless God & 2008 \\
\hline $248.4 \mathrm{CHA}$ & BV601.9.C47 2018 & Chan, Francis, 1967. & Letters the church (Lost item) & 2018 \\
\hline $248.4 \mathrm{CHA}$ & BV4501.2.C4754 1998 & Chan, Simon & Spiritual theology : a systematic study of the Christian & 1998 \\
\hline $248.4 \mathrm{CHA}$ & BV4647.J68.C464 1964 & Channon, Wilhelmina F. & The key to true happiness & 1964 \\
\hline $248.4 \mathrm{CHA}$ & BV4501.2.C435 1995 & Chant, Barry, 1938- & Breaking the power of the past & 1995 \\
\hline 248.4 CHA & BV4598.2.C435 1996 & Chant, Barry, 1938- & $\begin{array}{l}\text { Creative living : how to live the kind of life you've always } \\
\text { wanted to live, } 2^{\text {nd }} \mathrm{ed} \text {. }\end{array}$ & 1996 \\
\hline $248.4 \mathrm{CHA}$ & BV4598.2.C435 1987 & Chant, Barry, 1938- & How to live the kind of life you've always wanted to live & 1987 \\
\hline $248.4 \mathrm{CHA}$ & ВТ304.2.C435 2012 & Chant, Barry, 1938- & Living in the image of God & 2012 \\
\hline $248.4 \mathrm{CHA}$ & BV4501.2.C46 1980 & Chant, Barry, 1938- & The miracle of Calvary & 1980 \\
\hline $248.4 \mathrm{CHA}$ & BV4501.2.C48 1972 & $\begin{array}{l}\text { Chant, Kenneth David, } \\
\text { 1933- }\end{array}$ & Sitting on top of the world: guidelines to successful living & 1972 \\
\hline 248.4 CHA & BV4647.S4.C52 1981 & $\begin{array}{l}\text { Chantry, Walter John, } \\
\text { 1938- }\end{array}$ & The shadow of the cross : studies in self-denial & 1981 \\
\hline $248.4 \mathrm{CHA}$ & BV4509.5.C44 1986 & Chapian, Marie & Growing closer & 1986 \\
\hline $248.4 \mathrm{CHA}$ & BJ1581.2.C273 1984 & Chapian, Marie & Staying happy in an unhappy world & 1985 \\
\hline $248.4 \mathrm{CHA}$ & BV4509.5.C44 1989 & Chapian, Marie, 1938- & Close friendships : making them, keeping them & 1986 \\
\hline $248.4 \mathrm{CHA}$ & BV4501.2.C42 1983 & $\begin{array}{l}\text { Chapman, John } \\
\text { Charles, 1930-2012 }\end{array}$ & A fresh start... & 1983 \\
\hline $248.4 \mathrm{CHA}$ & BV4501.2 .C42 1997 & $\begin{array}{l}\text { Chapman, John } \\
\text { Charles, 1930-2013 }\end{array}$ & A fresh start & 1997 \\
\hline
\end{tabular}

FIGURE 4: An example of reclassification of DDC call number 
This finding suggested the shortcoming with the DDC system that it does not support the research community and research support service. Firstly, the user community needs to find information, drill down to the specific information, and carry out research tasks effectively and efficiently. Subsequently, they more often ask staff for reference assistance. This leads to an increase in the staff time at reference service and less priority being able to be directed to other essential tasks. In contrast, LCC has comprehensive facets that increase the discoverability of bibliographic data and improve researchers' productivity. It allows the researcher to narrow and widen the search scope. Secondly, LCC facets can support the librarian in organizing knowledge and information, evaluating collection strength, and analysing for collection development effectively and efficiently.

\section{Is DDC less biased than LCC?}

DDC has been criticized for its weakness of cultural and religious biase by scholars. Harvey and Hider (2004) made the criticism that DDC was US and Western, with Anglo-Saxon social and cultural bias. The criticisms of DDC from the Australian point of view have been aired frequently.

Chan and Salaba $(2007,2015)$ commented that an Anglo-American bias is particularly obvious in 900 (Geography and History), and 800 (Literature). Further, 200 (Religion) shows a heavy bias towards American Protestantism. Mai (2016) found that the editors of DDC noted in a blog post in 2006:

"We're the first to admit that the top-level view of 200 Religion in the DDC is problematic.” (Mai 2016)

In Dewey 23rd edition, it says, "In 200 Religion, they have initiated updates of provisions for the Orthodox Church and Islam; further work is planned on both of these areas after the publication of Edition 23.”

At the same time, Higgins (2016) was concerned that DDC lacked consistence and clarity of the definition of terms, such as 'race' and 'ethnic', and that led to systemic culture bias away from their original design for organising a universal knowledge system with no racial and religious bias. Lund and Agbjai (2018) also claimed that DDC was culturally biased, lacking breadth of classifying for non-Christian religions and non-white cultures. 
However, Noland (2017) compared LCC with the Judaic library classification system, Elazar, and made the criticism that LCC and DDC incorporated the Bible, Judaism, and Israel into a general, nonJewish world of knowledge without relating Jewish and Jewishoriented subjects to one another. He commented that LCC lacked specificity in organising Jewish content and that this was not necessarily viewed as a lack of support or interest in the Judaic way of life, but was rather part of the general problem of identifying specific topics within broad, standardized systems (Noland 2017). He suggested that terminology needs updating to allow for specific and broad searching contexts.

\section{Other considerations}

Other concerns were also taken into consideration that:

- The Chinese collection will lack support for classification and cataloguing from their counterparts if they choose to use DDC.

- Vendors provide LCC call numbers for electronic resources, e.g., from the Atla Religion and Philosophy database and e-books. The class number of electronic resources were not used for physical location, but it was used for other purposes, such as virtual browsing or collection development and maintenance (Bothmann 2004). Classification and reclassification are still relevant in the digital environment even in a mobile world (Steele and Foote 2011). If we chose to use DDC, the librarian will reclassify e-resources from LCC to DDC for resource management; as a result, it would increase the staff time for cataloguing and resource management.

\section{Decision Made and Implementation of Reclassification}

After careful consideration of the pros and cons, we finally decided to choose LCC over DDC to reclassify the entire Chinese theological collection. An implementation plan, budget, and timeline were developed; these were approved by the executives.

\subsection{Reclassification Project Preparation}

\subsubsection{Find the corresponding LC call number.}

The librarian and a volunteer librarian used free software, MarcEdit, to export bibliographical data and conduct batch searching with ISBN via Z39.50 to find 
the records with LC call number from other library catalogues.

Those records that could not be found from batch searching were searched from different library catalogues or had an LCC number assigned to them. Then the records were downloaded to MarcEdit.

7.1.2 Open MarcEdit's Merge Records function to merge records with the same ISBN and overlay tag 050 to our bibliographical records.

7.1.3 Prepare spreadsheet. We extracted the data to the Excel spreadsheet for other volunteers to change the item call numbers and print the new call number labels to replace the old ones.

7.1.4 Recruit volunteers and provide training.

7.1.5 Calculate the shelf space.

The librarian used the new call numbers to calculate the shelf space requirements and to map the location for different areas.

\subsection{Project Implementation}

7.2.1 The librarian relocated the identified area to the empty shelves as a temporary location. Then the volunteer began to relabel the items and shelved them by the LCC call number.

7.2.2 Returned items were changed to new call numbers before they were reshelved.

7.2.3 Monitor the project timeline and program.

7.2.4 Design and develop an online educational module about Library of Congress Classification in Chinese for users to learn at their own pace (Appendix 1). The librarian used educational software, Articulate, to develop an interactive program for students to learn about LCC structure, including class and subclass browsing, notation, and shelf order.

7.2.5 A survey for the online module evaluation was developed.

7.2.6 Conduct the Chinese Collection Subject Analysis with LC call numbers and facets and create a visualisa- 
tion chart to describe breadth and depth of the whole collection (Appendix 2).

\section{Outcomes}

8.1 The project completion was delayed due to multiple COVID lockdowns in Melbourne. Since the project relied on volunteers' contribution of their effort and time, the lockdowns prevented them from coming in the library to help on the project.

8.2 The project achieved the objectives and goals. Eighty percent of the collection has been converted to LCC call numbers.

8.3 There was no library service interruption or adverse effects on the users.

8.4 An online training module for users was successfully launched, which empowered users to master the classification system and ease their anxiety around the change.

We received positive feedback from a few users. A respondent commented, "The system is easy to follow with the list of information; suggest to put the subclass list or related information on somewhere we can easily access to help user to remember."

8.5 Increased staff productivity, in particular in cataloguing and accessioning, and reduced staff time at the reference desk and helping users to locate items in the library.

8.6 Improve collection management and increase its visibility. To illustrate:

8.6.1 LCC improved the discoverability and visibility of the Chinese collection. The users were able to use facets to drill down to special topics relating to their research and effectively retrieved information from the library systems and shelves.

8.6.2 English materials integrated well with Chinese language materials. Translated work can be placed side-by-side with the original work. It led to a question, 
"Should LOTE materials be separated from Main Collection if LCC can integrate different language materials?”

8.7 The librarian effectively conducted an in-depth collection analysis for Chinese Department, including quantities (counts of titles per area) and qualitative aspects (facets). She was able to evaluate the collections' strengths and weaknesses, i.e., identify collection gaps, and evaluate databases, acquisitions, and electronic resource subscriptions.

\section{Conclusion}

The reclassification of Chinese Theological Collection sheds light on information and knowledge organisation and management. It refreshes our understanding and information practice.

Classification is the foundation of knowledge organisation and a core business activity that supports many aspects of library service. These include collection development and acquisition, information retrieval and discovery, information literacy, research support, lending service, reference services, and user experience.

Classification improves technical services by increasing collection capacity, collection discoverability and visibility, and collection acquisition and maintenance. It improves user experience in discovering and retrieving information regardless of the physical and digital environments. It increases research capacity and aids research support services. It enhances the design and development of information literacy which become more engaging and interactive and facilitate teaching and learning. This results in enhancing the user's overall experiences in using the library service.

Classification is not merely for shelving and retrieving items in a library branch. Information professionals should strategically rethink and reposition classification and transform it into a valueadded service to the library.

\section{REFERENCES}

ACL. 2017. “Classification Systems.” ACL Library. https://e-resources. alc.edu.au/library-guides/Pages/Classification-systems.aspx.

ALA. 2020. "Dewey or LC? .” American Library Association. Accessed 3 June 2020. http://www.ala.org/tools/dewey-or-lc. 
Bothmann, Robert. 2004. “Cataloging Electronic Books.” Library Resources \& Technical Services 48 (1): 12-19.

Butler, Rebecca. 2013. "The Rise and Fall of Union Classification." Theological Librarianship 6 (1): Theological Librarianship. https:// doi.org/10.31046/tl.v6i1.254.

Chan, Lois May. 2007. Cataloging and Classification: An Introduction. Lanham: The Scarecrow Press, Inc.

Chan, Lois May, and Athena Salaba. 2015. Cataloging and Classification: An Introduction. Lanham: Rowman \& Littlefield Publishing Group, Incorporated.

Eisenhart, Ruth C. . 1960. "The Classification of Theological Books." Library Trends, 9, no. 1960: Current Trends in Theological Libraries (2): 257-269. http://hdl.handle.net/2142/5943.

Gangu, B.T., and R. Pommal Rao. 2002. "Classification, New Subjects and Dewey Decimal Classification Overcoming 18th edition. Limitations." Annals of Library and Information Studies 49 (1): 13-22. http://nopr.niscair.res.in/bitstream/123456789/4132/1/ ALIS\%2049\%281\%29\%2013-22.pdf.

Harvey, Ross , and Hilip Hider. 2004. Organising Knowledge in a Global Dociety: Principles and Practice in Libraries and Informtion Centres. Wagga Wagga: Cenre for Information Studies, Charles Sturt University.

Higgins, Molly. 2016. “Totally Invisible: Asian American Representation in the Dewey Decimal Classification, 1876-1996.” Knowledge Organization 43 (8): 609-621.

Lund, Brady D., and Daniel A. Agbaji. 2018. "What Scheme Do We Prefer? An Examination of Preference between Library of Congress and Dewey Decimal Cassification among US-based Academic Library Employees.” KO Knowledge Organization 45 (5): 380-392.

Mai, J-E. . 2016. "Marginalization and Exclusion: Unraveling Systemic Bias in Classification.” Knowledge Organization 43 (5): 324-330.

Noland, C. G. . 2017. "Classification Methods in Context at Theological Libraries: A Case Study.” SLIS Student Research Journal 7 (1). 
https://pdfs.semanticscholar.org/06bc/7d00a252767b7dabaf374a b8666df2cef39d.pdf.

Steele, Thomas D., and Jody Bales Foote. 2011. "Reclassification in Academic Research Libraries: Is It Still Relevant in an E-Book World?” Cataloging \& Classification Quarterly 49: 14-32.

Stevens, Kerrie. 2021. "ANZTLA 2020 Statistics.” The ANZTLA EJournal (26). https://serials.atla.com/anztla/article/view/2930/3638.

Walker, Christopher H, and Ann Copeland. 2009. "The Eye Prophetic: Julia Pettee.” Libraries \& the Cultural Record 44 (2): 162-82. https:// doi.org/10.1353/lac.0.0069.

\section{APPENDIX 1. USER TRAINING MODULE}

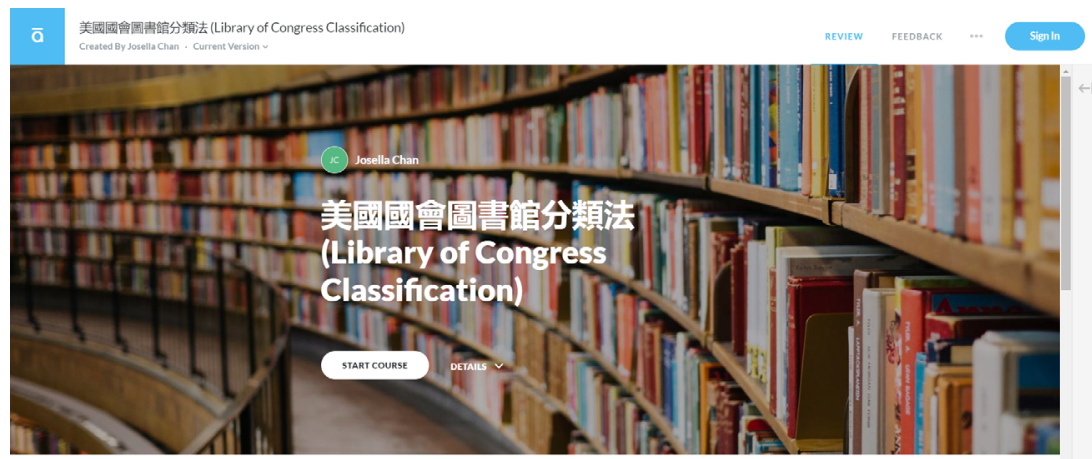


APPENDIX 2. GRAPHS FOR THE MSTC PRINT AND ELECTRONIC BOOKS COLLECTION SUBJECT ANALYSIS WITH LC CALL NUMBER AND FACETS

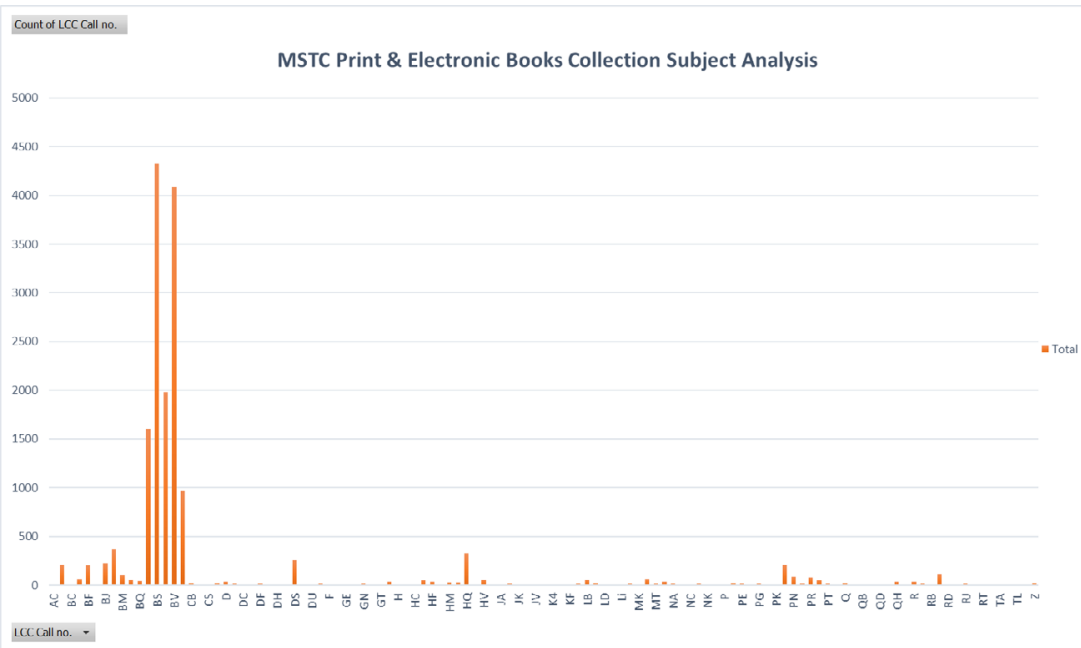

FIGURE 5: MSTC Print and Electronic Books Collection Subject Analysis with LC call numbers

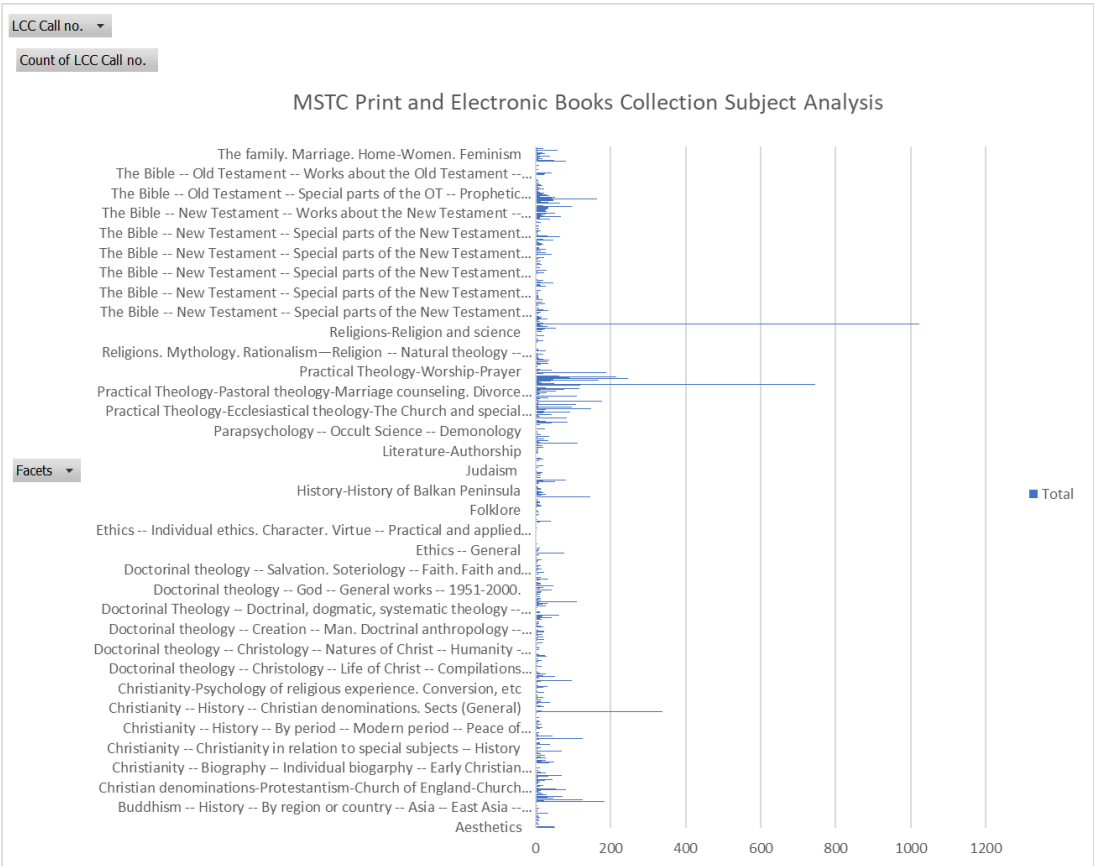

FIGURE 6: MSTC Print and Electronic Books Collection Subject Analysis with facets 